\title{
FORMAÇÃO DE PROFESSORES NO SÉCULO XIX E A ARITMÉTICA DE CONDORCET: espectros de vozes em revistas da instrução pública
}

\author{
Kátia Sebastiana Carvalho dos Santos Farias ${ }^{1}$ \\ Anna Regina Lanner de Moura² \\ Antonio Miguel 3
}

\section{RESUMO}

Este artigo tem como objetivo problematizar o uso privilegiado do Manual de Aritmética de Condorcet, intitulado Meios de aprender a contar seguramente e com facilidade, divulgado no Brasil, no século XIX, em revistas da instrução pública, discutindo ao mesmo tempo as potencialidades de fontes constituídas por revistas de cunho pedagógico, desse período, que tratam da prática escolar da Aritmética e da formação de professores primários. Essa problematização tem referência na base documental da tese de doutorado de Farias (2014) que analisa os usos de revistas e jornais como práticas mobilizadoras de cultura aritmética, que teriam circulado na Escola Normal da Província do Rio de Janeiro, no período de 1868 a 1889, com o propósito de formar professores para atuarem no ensino da matemática nas chamadas "escolas de primeiras letras". Esta investigação assumiu a natureza da pesquisa no campo da História da Educação Matemática no Brasil, tomando como inspiração a terapia filosófica de Wittgenstein e o pensamento de desconstrução de Derrida que defendem a inexistência de conhecimento e de pensamento independentes, respectivamente de jogos de linguagem ou de escritura. Neste artigo, ressaltamos a importância da temática da formação e práticas de professores uma vez que, na segunda metade do século XIX, essa temática era assunto de grandes debates e discussões. Além disso, o destaque que se confere à Escola Normal da Província do Rio de Janeiro, em Niterói, é devido ao fato de esta escola ter sido a primeira Escola Normal criada no Brasil, em 1835, para formar professores primários.

Palavras-chave: Aritmética de Condorcet. Formação de professores no século XIX. Ideais iluministas.

\footnotetext{
1 Doutora em Educação, Professora do Programa de Mestrado Profissional em Educação Escolar (MEPE), da Universidade Federal de Rondônia. E-mail: katiafarias2014@gmail.com

2 Doutora em Educação, Professora livre-docente pela Faculdade de Educação da Universidade Estadual de Campinas - UNICAMP/Campinas-BRASIL. E-mail: lanner4@gmail.com

3 Doutor em educação, Professor livre-docente pela Faculdade de Educação da Universidade Estadual de Campinas - Unicamp. E-mail: miguel37.unicamp@gmail.com
} 


\title{
TEACHER EDUCATION IN THE NINETEENTH CENTURY AND CONDORCET'S
}

\author{
ARITHMETICS: voice spectra in public education magazines
}

\begin{abstract}
This paper aims to problematize the privileged use of Condorcet's Arithmetic Manual, titled Means of learning to count easily and precisely, published in Brazil in the nineteenth century in public instruction journals, while discussing the potentialities of constituted sources by pedagogy-oriented journals of this period, which deal with the school practice of Arithmetic and elementary school teacher education. This problematization is supported by the documentary basis of the doctoral thesis of Farias (2014), which analyzes the uses of magazines and newspapers as mobilizing practices of an arithmetic culture that would have circulated in the Normal School of the Rio de Janeiro province, from 1868 to 1889, with the purpose of preparing Mathematics teachers for the so-called "schools of first letters." Based on the field of History of Mathematical Education in Brazil, this investigation is inspired by the philosophical therapy of Wittgenstein and Derrida's deconstructionism, especially his postulation of the inexistence of independent knowledge and thought respectively of language or writing games. In this paper, we emphasize the importance of the themes of teacher education and teacher practices since, in the second half of the nineteenth century, these themes were objects of heated debates and discussions. In addition, the emphasis given to the Normal School of the Province of Rio de Janeiro in Niterói is due to the fact that this school was the first Normal School created in Brazil in 1835 for preparing elementary school teachers.
\end{abstract}

Keywords: Condorcet's arithmetic. Teacher education in the nineteenth century. Illuminist ideals.

\section{FORMACIÓN DE PROFESORES EN EL SIGLO XIX Y LA ARITMÉTICA DE CONDORCET: espectros de voces en revistas de la instrucción pública}

\section{RESUMEN}

Este artículo tiene como objetivo problematizar el uso privilegiado del Manual de Aritmética de Condorcet, titulado Medios de aprender a contar de manera segura y con facilidad, popularizado en Brasil en el siglo XIX, en revistas de instrucción pública, discutiendo al mismo tiempo las potencialidades de fuentes constituidas por publicaciones científicas de ámbito pedagógico de ese período, que tratan de la práctica escolar de la Aritmética y de la formación de profesores de la educación primaria. Este cuestionamiento tiene referencia en la base documental de la tesis de doctorado de Farias (2014) que analiza los usos de revistas y periódicos como prácticas movilizadoras de cultura aritmética que fueron divulgadas en la Escuela Normal de la Provincia de Río de Janeiro, en el período de 1868 a 1889, con el propósito de formar profesores para actuar en la enseñanza de las matemáticas en las llamadas "escuelas de primeras letras". Esta investigación asumió la naturaleza de la investigación en el campo de la Historia de la Educación Matemática en Brasil tomando como inspiración la terapia filosófica de Wittgenstein y el pensamiento de deconstrucción de Derrida que defienden la inexistencia de conocimiento y de pensamiento independientes, respectivamente de los juegos de lenguaje o de 
escritura. En este artículo, resaltamos la importancia de la temática de la formación y prácticas de profesores una vez que, en la segunda mitad del siglo XIX, esa temática era objeto de grandes debates y discusiones. Además, el destaque que se confiere a la Escuela Normal de la Provincia de Río de Janeiro, en Niterói, es que esa institución fue la primera Escuela Normal creada en Brasil, en 1835, para formar profesores de la educación primaria.

Palabras clave: Aritmética de Condorcet. Formación de profesores en el siglo XIX. Ideales iluministas.

\section{INTRODUÇÃO}

Por entendemos que revistas, jornais e periódicos constituem, dentre outras, fontes confiáveis e realistas para uma descrição das práticas educativas escolares que teriam sido realizadas no Brasil do século XIX, o objetivo deste artigo é problematizar o uso positivista do Manual de Aritmética de Condorcet - publicado, no Brasil, com o título Meios de aprender a contar seguramente e com facilidade 4 , bem como, divulgado em forma de fascículos, em revistas da instrução pública - como fonte privilegiada de difusão dos ideais iluministas. Temos ainda como propósito, discutir as potencialidades de revistas brasileiras, de cunho pedagógico, do século XIX, como fontes historiográficas para a pesquisa contemporânea das práticas escolares de ensino da Aritmética e da formação de professores primários no Brasil do século XIX.

Esta problematização toma como referência destacada, a base documental da tese de doutorado de Farias (2014) que analisa os usos das revistas - A Revista do Ensino; Revista Brasileira de Educação e Ensino; Revista do Ensino Primário -, bem como, dos Jornais - A Instrução Pública; A Verdadeira Instrução Publica - como fontes para uma descrição fidedigna e realista de práticas de ensino de aritmética que teriam sido realizadas na Escola Normal, da Província do Rio de Janeiro, no período de 1868 a 1889 , com o propósito de formar professores para atuarem nas chamadas "escolas de primeiras letras". A investigação historiográfica de Farias assume o pressuposto pós-epistemológico central do pensamento último do filósofo austríaco Ludiwig Wittgenstein, da impossibilidade de produção autônoma

\footnotetext{
${ }^{4}$ Condorcet (1883); Condorcet (1903).
} 
de conhecimentos ou saberes, que sejam independentes de jogos de linguagem, entretecidos em diferentes formas de vida - isto é, de modos efetivos de humanos lidarem corporalmente com signos, visando a propósitos diversos - bem como, de pressuposto análogo ao pensamento do filósofo franco-argelino Jacques Derrida, do primado da escritura em relação a qualquer forma autônoma de conhecimento. Com base nesses pressupostos, Farias percorre, nas revistas acima referidas, as diferentes práticas de formação de professores para o ensino da matemática - vistas como jogos de linguagem - que elas descrevem, analisam, criticam ou, simplesmente, fazem referência.

Neste artigo, ressaltamos a importância das práticas de formação de professores, uma vez que, na segunda metade do século XIX, elas eram tema de grandes debates e discussões em nosso país. Além disso, o destaque que conferimos à Escola Normal da Província do Rio de Janeiro, em Niterói, se deve ao fato de ela ter sido a primeira Escola Normal criada no Brasil, em 1835, para formar professores primários.

Tal como Miguel (2010), entendemos que uma das exigências de pesquisas de natureza historiográfica que se realizam sob a perspectiva filosófica em que nos colocamos é a constituição de um arquivo de práticas específicas pertinentes ao propósito da investigação, práticas estas que, no contexto da presente investigação, precisam ser vistas como jogos de linguagem, que se realizaram no contexto espaço temporal especificado, do campo de atividade, da formação de professores em nosso país.

Grande parte dos textos que integra o arquivo da pesquisa de Farias (2014) - e que fazem referência a tais práticas - pode ser acessado no setor de obras raras, da Biblioteca Nacional do Rio de Janeiro, ou no Arquivo Público do Estado do Rio de Janeiro. Para dar maior visibilidade às suas fontes da pesquisa, a autora organizou um quadro no qual apresenta as revistas analisadas, bem como, os atores/comunidades e as práticas de ensino de aritmética realizadas, quer no contexto da formação de professores, quer no contexto das então denominadas "escolas de primeiras letras". 
QUADRO 1: Fontes da pesquisa

\begin{tabular}{|l|l|l|l|}
\hline $\begin{array}{l}\text { Tipificação } \\
\text { da fonte }\end{array}$ & $\begin{array}{l}\text { Especificação da fonte } \\
\text { constituída }\end{array}$ & $\begin{array}{l}\text { Autores, atores } \\
\text { e/ou } \\
\text { comunidades } \\
\text { destinatárias }\end{array}$ & $\begin{array}{l}\text { Contextos de atividade } \\
\text { humana cujos rastros de } \\
\text { memória são mobilizados } \\
\text { por práticas aritméticas }\end{array}$ \\
\hline \multirow{5}{*}{ Revistas } & $\begin{array}{l}\text { O Ensino Primario (mensal, } \\
\text { redigida por professores } \\
\text { primários da Província do } \\
\text { Rio de Janeiro) } \\
\text { Revista do Ensino editada } \\
\text { mensalmente. }\end{array}$ & $\begin{array}{l}\text { Professores } \\
\text { Formadores } \\
\text { A Escola: Revista Brasileira } \\
\text { Le Educação e Ensino } \\
\text { mensal }\end{array}$ & $\begin{array}{l}\text { Atividades midiáticas em } \\
\text { geral; Atividade de mídias } \\
\text { formativas, educativas } \\
\text { e/ou voltadas para } \\
\text { professores, pais e } \\
\text { autoridades escolares. }\end{array}$ \\
& & \\
\hline
\end{tabular}

Fonte: Farias (2014).

Uma destas revistas - A Revista do Ensino - publicava fascículos da Arithmetica de Condorcet, assunto que trataremos posteriormente.

O encaminhamento metodológico utilizado por (FARIAS, 2014) em sua pesquisa, foi o de constituir e ressignificar as práticas mobilizadas pelos textos do arquivo da pesquisa, por entender que numa prática de investigação historiográfica, o que o historiador na realidade faz, é lutar contra as armadilhas, nas quais os jogos de linguagem nos envolvem, quando temos como propósito significar adequadamente tais práticas (MIGUEL, 2010). Nesse sentido, a autora lidou com jogos de linguagem performados, ou seja, encenados segundo o gênero cênico-teatral, gênero pouco usual de se praticar a escrita de uma investigação historiográfica acadêmica, mas que Ihe possibilitou, de modo dialógico, nos rastros de outros jogos de linguagem, lidar satisfatoriamente com a questão norteadora da pesquisa (FARIAS, 2014).

Sob esta perspectiva, não entendemos que as revistas constituam, por si mesmas, uma fonte historiográfica para se identificar ou descrever algo. Pensamos que, quando lemos essas fontes, mobilizados pelo propósito da pesquisa, descompactamos jogos de linguagem, visando produzir uma narrativa contemporênea. Tal narrativa, ao mesmo tempo em que descompacta, produz uma nova compactação desses jogos de linguagem que, em nosso tempo e em novos contextos, adquire uma nova força e potencializa novos efeitos sobre os leitores de nossa época. Assim, 
procedemos por entendermos que esse tipo de fonte mobiliza práticas realizadas por humanos de determinado tempo cronológico, situados em um campo de atividade humana especificado, qual seja, o da formação de professores, para atuarem nas denominadas "escolas de primeiras letras", que fazem diferentes usos do tempo no interior desse campo. De forma análoga, entendemos que os estudos historiográficos em educação matemática buscam compreender diferentes modos, como as práticas de ensino de matemática, se realizam sob os condicionamentos das transformações temporais de diferentes campos e contextos de atividade humana que, de algum modo, se preocuparam com a transmissão de jogos normativos de linguagem, isto é, de jogos que não apenas pré-definem os propósitos a serem atingidos pelos participantes do jogo, como também, produzem algoritmos que permitem atingir inequivocamente tais propósitos (FARIAS, 2014); (MIGUEL, 2010).

\section{REVISTAS COMO MÍDIAS FORMATIVAS, EDUCATIVAS E/OU VOLTADAS PARA PROFESSORES}

Antes de enfocarmos aspectos específicos, convidamos os leitores para seguir conosco, rastros da expansão do campo de atividade humana, constituído com o propósito de se produzir e divulgar materiais impressos. Embora tais rastros - numa concepção ampla de impressão, como inscrição em qualquer tipo de suporte material - estejam difusos e dispersos desde o advento do homo sapiens na história, eles podem ser buscados no mundo europeu, numa concepção mais restrita de impressão, pelo menos desde a invenção da prensa móvel por Johanes Gutenber, em 1450, momento em que tal expansão se ampliou consideravelmente, e mais precisamente, no interesse de nossa pesquisa, na França do século XIX. Entendemos, com Mollier (2008, p. 8), que o advento do jornal impresso - que inseriu o romancefolhetim em sua primeira página a partir dos anos 1836-1839 -, bem como o do jornal popular a um centavo - como, por exemplo, o Le Petit Journal de 1863 -, e o das revistas dos anos 1850-1860, constituíram as bases materiais da massificação da prática da leitura de textos impressos. 
No Brasil, a instituição da imprensa marcou o desenvolvimento de novas práticas de leitura, uma vez que, além dos documentos oficiais, passou-se também a imprimir outros gêneros de textos, neles incluídos os de cunho científico e literário (JINZENJI, 2010). No entanto, a ampliação na circulação dos impressos foi seguida de medidas de controle, por parte da Corte brasileira ${ }^{5}$. Dessa forma, a imprensa periódica se constituiu como elemento importante para a cultura política do século XIX brasileiro, tendo sido sua forte produção e circulação sustentadas, quase sempre, pelas atividades políticas desenvolvidas naquele tempo. Assim, a imprensa periódica acabou difundindo, entre os seus leitores, uma certa maneira de pensar e significar as práticas que se realizavam em diferentes campos de atividade humana. No início do desenvolvimento da imprensa no Brasil, o jornalista se confundia com o educador. De certa forma, o jornalista supria a carência de escolas e de livros didáticos por meio de seus escritos jornalísticos (BASTOS, 2002). A força dessa ideia permaneceu durante as primeiras décadas do século XIX, quando o processo de escolarização ainda não havia se consolidado na Província do Rio de Janeiro (FARIAS, 2014). Assim como na Europa, as revistas pedagógicas e os jornais produzidos no Brasil do século XIX tinham como princípio difundir o ideário e os valores de um projeto iluminista política e epistemologicamente transfigurado pelo positivismo Comteano, o que, em outras palavras, significava educar e sensibilizar o público leitor para a necessidade de sua adesão e inserção em um projeto civilizatório de cunho liberal, doutrinário, cientificista e conservador. Sobretudo após a conquista da independência, "a imprensa passou a ser constantemente referida como meio mais eficiente e poderoso de influenciar os costumes e a moral pública, discutindo questões sociais e políticas" (PALLARES-BURKE, 1998 apud JINZENJI, 2010, p. 25.)

\footnotetext{
5 A liberdade de imprensa seria posta no papel pelo Decreto de 18 de junho de 1822, que vigorou até 1823; finalmente, passou a compor o artigo 179, no item IV da Constituição do Império, segundo o qual "todos podem comunicar os seus pensamentos, por palavras, escritos, e publicá-los pela Imprensa, sem dependência de censura", salvo em casos de abuso (JINZENJI, 2010, p. 47).
} 
A Província do Rio de Janeiro, por volta dos anos de 1870, vivia períodos de efervescência e de profundas mudanças na política e na sociedade. Esse clima é próprio do Brasil imperial depois da Guerra do Paraguai, um país em que a escravidão fazia ainda sentir sua presença de forma ainda marcante e em que a educação escolar, ainda muito restrita, começava a se configurar como preocupação dos governos, com ênfase na necessidade de se formar professores de primeiras letras. Nesse clima, os professores do magistério público primário da Província do Rio de Janeiro, muitos deles formados na Escola Normal, discutiam problemas educacionais e sociais que julgavam importantes, bem como publicavam suas ideias (FARIAS, 2014).

Em duas diferentes mídias impressas - revistas e jornais -, produzidas no interior de um mesmo campo de atividade humana - o campo do jornalismo impresso - professores questionavam as decisões políticas do império brasileiro, que eram tomadas única e exclusivamente na Corte, sede da monarquia. Os professores primários encontravam-se numa posição não apenas de cumpridores de uma política pensada de fora da categoria, mas também, de questionadores e propositores de novas políticas. Assim, com Borges e Lemos (2009), entendemos que, na segunda metade do século XIX, aumentavam as reivindicações de professores, escritas de protestos em que eles se colocavam diante de uma vasta gama de assuntos: reclamavam, opinavam, pediam e elaboravam propostas de forma organizada, reunindose e escrevendo.

Cabe salientar que, dentre outros periódicos, as revistas A Revista do Ensino, A Escola: Revista Brasileira de Educação e Ensino e a Revista do Ensino Primário circulavam na Província do Rio de Janeiro, uma vez que, na segunda metade do século XIX, circulava na Província um variado número de revistas e jornais, alguns conhecidos como grandes jornais, tais como o Jornal do Commercio, a Gazeta de Notícias, a Gazeta da Tarde, e o Diário do Rio de Janeiro. Já algumas publicações eram voltadas para um público específico, como, por exemplo, os periódicos destinados às mulheres (Borges e Lemos, 2009, p. 3). No caso do Rio de Janeiro, havia o Jornal das Moças 
Solteiras, o Jornal das famílias e o Correio das Damas, e, semelhantemente, o periódico O Mentor das Brasileiras, que foi o primeiro periódico de São João Del-Rei, e que se propunha a "promover a instrução e o entretenimento do belo sexo". Tais periódicos divulgavam receitas, figurinos, conselhos de beleza, pequenas histórias de amor e, junto com tudo isso, tentavam ditar o comportamento moral feminino, considerado politicamente correto e aceito pela sociedade.

Revistas pedagógicas

A Revista do Ensino e a Revista do Ensino Primário estão no rol de revistas pedagógicas criadas no ano de 1882, na Corte brasileira. Suas edições ocorriam mensalmente, organizadas em fascículos de dezesseis páginas, e funcionavam como veículos de divulgação das ideias dos professores públicos primários. Aproveitando bem o momento de liberdade de imprensa, os professores públicos do magistério primário também fizeram um uso crítico dessa mídia.

FIGURA 1: A escola - Revista de Educação e Ensino

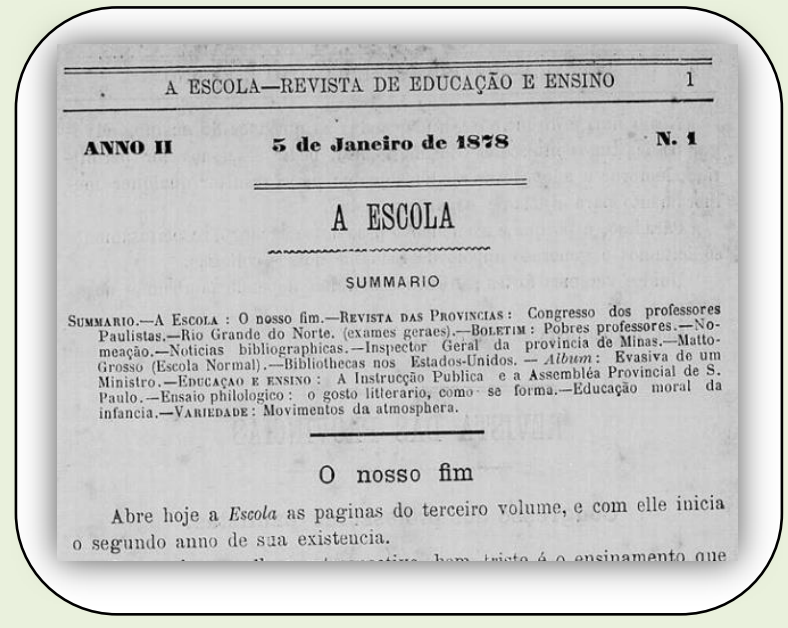

Fonte: Farias (2014).

A Revista A Escola - Revista de Educação e Ensino está disponível na Fundação Biblioteca Nacional/RJ. Trata-se de uma revista que teve o seu primeiro número no ano de 1877, com a colaboração de vários professores e 
literatos. Foi dirigida por Dr. Luiz Joaquim Duque-Estrada Teixeira, deputado fluminense e membro do Partido Conservador. A Escola foi um importante periódico que discutia educação e ensino. O primeiro número afirmava que o objetivo da escola se decompõe em três ideias capitais: ministrar um meio de instrução às classes menos favorecidas pela fortuna; reunir, para o professorado, as notícias, informações e esclarecimentos que poderiam ser obtidos em referência aos sistemas de educação e métodos de ensino; defender os direitos e legítimos interesses do magistério, público e particularb.

FIGURA 2: A escola - Revista de Educação e ensino

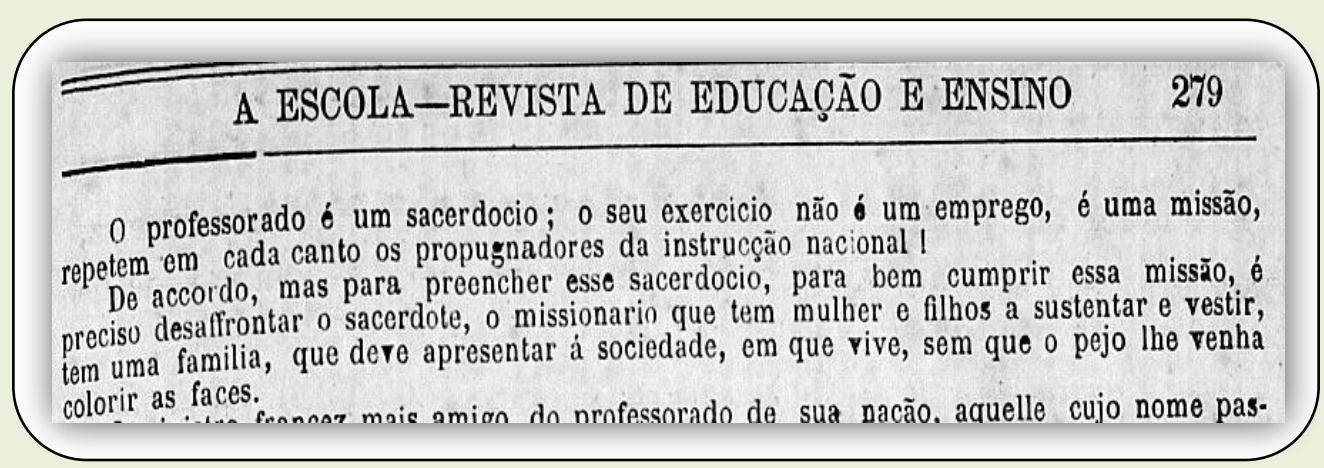

Fonte: Farias (2014).

A revista foi também foi um espaço de discussão e de questionamentos por parte de professores primários. Eles reclamavam, por exemplo, das condições de trabalho, conforme podemos ver na imagem acima.

\section{REVISTAS PEDAGÓgICAS ENCENAM IDEIAS DE PROFESSORES PÚBLICOS PRIMÁRIOS}

Trazemos a seguir um excerto de um dos jogos de cenas da tese de Farias (2014), com a intenção de levar ao leitor um entendimento da forma como, nela, a autora mobilizou as fontes aqui citadas.

Cenário: Uma sala de reuniões na Escola Normal da Província do Rio de Janeiro. O palco teatral-divã acontece numa manhã do dia 11 de novembro do ano de 1888, na Imperial Cidade, Niterói, capital da briosa

${ }^{6}$ Revista A Escola: Revista Brasileira de Educação e Ensino (1877, p. 3). 
Província do Rio de Janeiro. Encenam no palco três personagens ficcionais: Alambary Luz, Maria Brasil e Severino da Costa. Farias (2014) criou as personagens, a partir de nomes de pessoas diretamente ligadas ao contexto educacional e de formação de professores da Escola Normal, da Província do Rio de Janeiro, no período estudado, com exceção da Maria Brasil, personagem criada com dupla inspiração, uma na obra As noites do Ginásio: teatro e tensões culturais na Corte, de Silvia Cristina Martins de Souza, e a outra, na vida da atriz e ativista política italiana Marietta Maria Baderna?.

Ou seja, nos jogos narrativos encenados, algumas personagens encenam um discurso "progressivista", tanto no sentido positivista, inscrito no lema "ordem e progresso" da bandeira brasileira, quanto no sentido da instauração de crenças liberais desenvolvimentistas e redentoras em todos os planos: político, educativo, escolar, cultural, familiar, individual etc. do projeto político-pedagógico civilizatório. Por sua vez, outras personagens atuam encenando um discurso "libertário", desestabilizador da ordem dominante, com raízes, na época, no discurso anarquista. Tais discursos "libertários", se colocam no diálogo como desconstrutores do projeto civilizatório, cujo ideário é mobilizado no contexto da atividade de formação de professores, da Escola Normal, da Província do Rio de Janeiro, pela ideologia liberal-republicana. Já, o discurso da personagem Maria Brasil é encenado com base em rastros de significação, provenientes dos campos literário e teatral de atividade humana.

O bonde elétrico! Barca a vapor! Frutos da modernidade. Passava pouco depois das oito horas. Os convidados para a reunião já estavam presentes. Agora, cada um buscava lugar para assentar-se nas cadeiras disponibilizadas em uma pequena sala na Escola Normal. Após trocas de breves cumprimentos e de alguns afetuosos apertos de mãos entre os presentes, teve início a reunião.

\footnotetext{
7 Marietta Maria Baderna (1828-1870). Militante, por ocasião política, exilou-se com o pai no Brasil, em 1849. Estabeleceram-se no Rio imperial, onde Marietta fez grande sucesso no palco. Conhecida como Maria Baderna, tinha estilo transgressor e libertário; de personalidade rebelde, vivia de forma excessivamente liberal para o Brasil de D. Pedro.
} 
(...)

ALAMBARY LUZ - Sim, senhores! O magistério é um grande ofício, um sacerdócio, ao qual estão confiados os "interesses da infância", o progresso dos discípulos e o futuro do país! O professor, em seu pequeno templo, a escola, ministrará o saber e, principalmente, uma cultura.

MARIA BRASIL - (Corta, visivelmente nervosa) O professorado é um sacerdócio? O seu exercício não é um emprego? É uma missão... repetem em cada canto os propugnadores da instrução nacional. Digamos que sim, mas para preencher esse sacerdócio, para bem cumprir essa missão é preciso desafrontar o sacerdote. O missionário tem mulher e filhos a sustentar e vestir... Tem uma família que deve apresentar à sociedade em que vive, sem que o pejo the venha colorir as faces...?.

SEVERINO DA COSTA - (Ignorando as palavras de Brasil) Belas palavras, senhor Luz! Daí a necessidade de atenderem aos justos reclamos do professor que, procurando ser zeloso, procura e deseja o bem maior de seus alunos, porque como "cavouqueiro que abre fossos" para os alicerces de grandioso edifício, é ele em cujas obras assentam todos os esteios da civilização ${ }^{10} \ldots$

MARIA BRASIL - (Corta. Indignada, chama a atenção de todos) Senhores! Perdoem-me dizer o que penso, mas não consigo entender o discurso dos senhores!

MARIA BRASIL - (Continua falando, visivelmente exaltada) esta não é a minha voz, é um eco! Um clamor das vozes dos professores imperiais, os pobres professores formados na Escola Normal da Província do Rio de Janeiro! Sim! Oficialmente há uma ideia forte: desprestigiar o professor público. Podemos ouvir muitas vozes... O clamor das vozes que se levantam

\footnotetext{
8 Jornal A Instrução Publica (n.3, de 28 de abril, 1872).

9 Revista A Escola: Revista Brasileira de Educação e Ensino (1878, p. 279). Artigo denominado O magistério e o Ensino: o magistério primário. Autor identificado como Y.

10 Revista A Escola: Revista Brasileira de Educação e Ensino (1878, p. 8). Artigo denominado Educação e Ensino: o professor público primário. Autor: Professor Padre Augusto Ferreira de Campos.
} 
pelo órgão da imprensa na folha denominada A Verdadeira Instrução Publica...

(Pequena pausa, todos olham para Maria Brasil, alguns franzindo a testa).

SEVERINO DA COSTA - (Concordando) Sim! É certo o que diz a senhora Brasil! Ouçamos a voz do professor Frazão: "O meio de tirar a instrução pública do estado em que se acha não é regularizar o processo mecânico do ensino, como pode parecer aos que veem de fora". Felizmente, para nós e para a mocidade do Rio de Janeiro, temos em sua excelência, o Senhor Inspetor Geral, um chefe que, além de responsável por suas luzes e por seu bom senso, encaneceu nas lides do magistério; o que quer dizer que em seu coração acharão eco as queixas pungentes de uma classe desvalida e voltada ao desprezo e à miséria ${ }^{11}$...

MARIA BRASIL - (Corta) Mas, por outro lado, os professores já estão se organizando enquanto classe. Estão se fortalecendo mutuamente.

Nos jogos narrativos aqui encenados podemos ver, como nos diria Derrida, uma reunião ou ligação de fios que nos permite ouvir a voz espectral do positivismo de Comte. Que fios são esses? Por exemplo: as expressões "o progresso"; "o sacerdócio"; "todos os indivíduos". Com Tiski (2005, p. 212), compreendemos que o positivismo vem sistematizar o estado definitivo que resulta espontaneamente do conjunto da preparação humana. Nesse processo de sistematização, o papel do intelectual é indispensável: o poder do sacerdócio é, sem dúvida, essencialmente intelectual. O sacerdócio se liga, assim, à existência doméstica, pelas leis morais que ela faz constantemente sentir. Ele liga umas às outras pelas leis intelectuais, que constituem seu próprio domínio. Em todos os sentidos, "o progresso é o desenvolvimento da ordem". Da ordem imposta (espontânea) à ordem (sistemática), assumida consciente e livremente. A moral, como ciência e como arte, é o conhecimento do homem e da humanidade (teoria); a construção do homem e da humanidade (prática). Para poder

\footnotetext{
11 Jornal A Verdadeira Instrução Publica, Ineditoriais (1872, p. 2).
} 
ser, ao mesmo tempo, teoria e prática, ela é o núcleo da religião e, na sua parte prática, identificada com a educação. Com Comte, a educação fornecia, de certo modo, o local para a moral, suprindo a falta do templo; como a moral, voltando a ser ciência distinta, precisava de um "tratado", a educação foi identificada com uma parte prática da moral, de maneira que assim se justifica o tratado de moral a partir do tratado sobre a educação ${ }^{12}$.

Enfatizamos que Comte recomendava 150 (cento e cinquenta) obras para a Biblioteca Positivista, dividida em 4 partes: Poesia, Ciência, História e Síntese. Das recomendações da Ciência, a primeira obra é a "Aritmética de Condorcet" (COMTE, 1983, p.134).

\section{O ENSINO INTUITIVO EM REVISTAS DA INSTRUÇÃO PÚBLICA}

O Brasil do final do século XIX transitava do sistema monárquico para o republicano. Do ponto de vista educacional, estava em curso uma transição entre "práticas tradicionais" - que investiam no ensino baseado na repetição e na memorização de conteúdos, desconectados de quaisquer práticas extraescolares, isento de inovação metodológica - e práticas pedagógicas "inovadoras", mobilizadoras do ideário da Pedagogia Moderna, que propunha a adoção do então denominado "método intuitivo", que privilegiava o aprendizado por meio das experiências dos sentidos, e o ensino pelas coisas, pelas ilustrações, pelas práticas de exercícios, pelo próprio esforço do aluno em descobrir as soluções dos problemas.

Assim, o contexto político e social no Brasil, em 1883, ano da primeira publicação da Aritmética de Condorcet em português, passava por mudanças econômicas, políticas, sociais e educacionais, marcado principalmente pela Reforma de Rui Barbosa (1883). Neste momento, o método de ensino intuitivo está em evidência, substituindo os métodos mnemônicos e repetitivos que, até então, eram praticadas nas escolas de primeiras letras.

12 Tiski (2005, p. 212). 
Alguns artigos de revistas dessa época abordam a dificuldade que alguns professores tiveram com o método intuitivo. De fato, o professor Estevão ${ }^{13}$ escreveu sobre a ineficácia do método lição de coisas. Ele não se posiciona contrariamente aos métodos de intuição. Entretanto, diz que o método de ensino intuitivo, embora constituísse um modo de ensinar que proporcionava às crianças ideias sãs da moral, da ordem, do útil, do belo e noções exatas sobre os objetos e assuntos que nos cercam no mundo físico e moral, não encontra espaço no país, cuja instrução circula ainda de forma lenta ${ }^{14}$.

Muitos dos professores daquela época entendiam o método intuitivo, como sendo aquele que deixava de lado a teoria para dedicar-se exclusivamente à prática, à prática e mais prática; que apresentava muitos exemplos, mas poucas regras; muitas aplicações, mas poucas teorias e abstrações, principalmente com relação ao ensino e à aprendizagem da Aritmética. Entretanto, encontramos impressos pedagógicos que defendiam a valorização das lições de coisas, argumentando que as crianças, por si próprias, absorvem as coisas que as cercam e adquirem muitas noções sobre elas; e ainda que essas noções, assim adquiridas, pudessem ser, em grande parte, errôneas e incompletas, as lições de coisas propunham-se a corrigi-las e sistematizá-las em um plano, de modo que elas apresentavam um progresso natural, legítimo e assaz fecundo em resultados ${ }^{15}$.

Um artigo denominado Museu escolarib, publicado em um número da Revista O Ensino Primário, trazia exemplos do uso de lições de coisas em outros países:

\footnotetext{
13 Antonio Estevão da Costa e Cunha foi professor da $3^{\circ}$ escola pública de Santa Anna da Corte do Rio de Janeiro. Teve experiência com o sistema de formação pela prática, no interior das escolas primárias, tendo servido de adjunto das escolas públicas entre os anos de 1860 e 1870. Foi professor primário e secundário, autor de obras didáticas e colaborador no Jornal A Instrução Publica, no período de 1872-1874.

14 Jornal A Instrução Publica, n. 7, 1872, p. 50.

15 Revista do Ensino. Artigo Notas da carteira de um educador (Ano VI, 1883, p. 57).

${ }_{16}$ Museu escolar que devia fornecer os objetos à intuição, organizar programas, metodizar o ensino intuitivo. Revista O Ensino Primario, 1884, p. 28.
} 


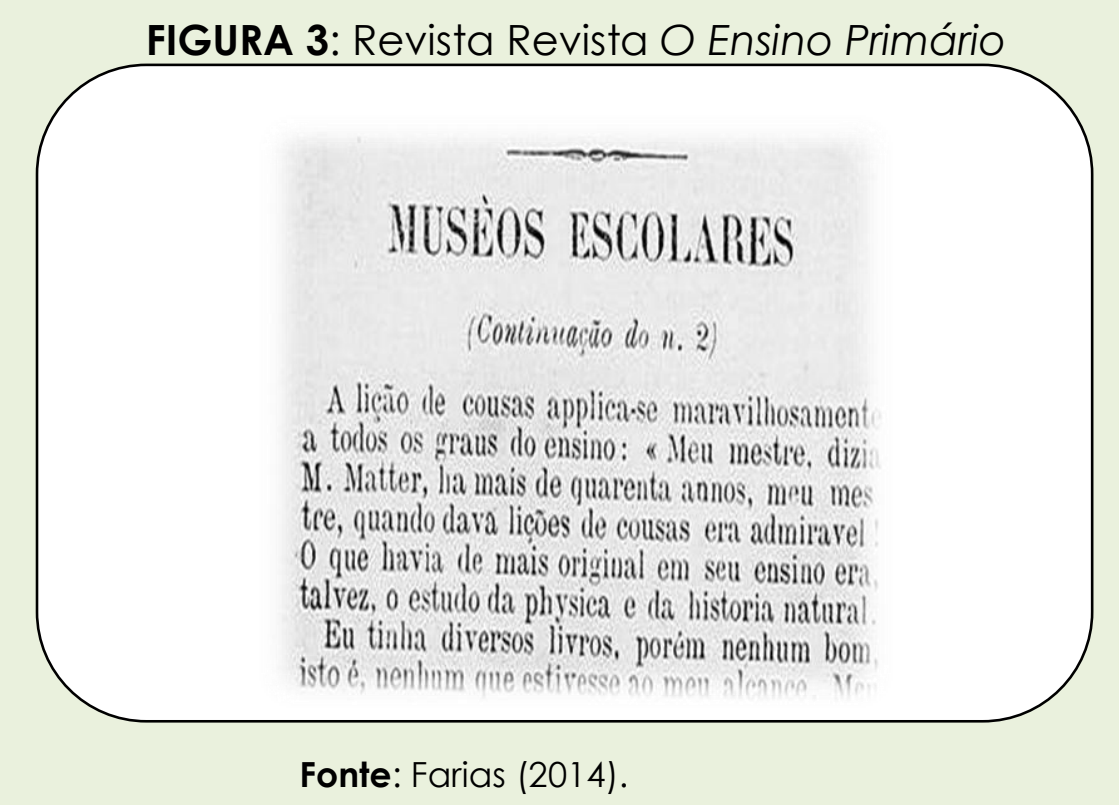

Vimos que, na Revista O Ensino Primário, a lição de cousas, também conhecida como método intuitivo, contrariamente aos métodos ditos tradicionais - que faziam preceder o conhecimento da palavra ao do objeto que ela buscava significar, e que confiavam à memória sons, em vez de gravar na inteligência ideias - começa por colocar sob os olhos da criança o objeto que faz o assunto da lição ou, na falta deste, a imagem que o representa; e, fazendo-lhe notar a sua cor, forma, uso, procedência e propriedades, por meio de questões habilmente formuladas, desperta na criança a observação, desenvolve-lhe a reflexão e exercita-lhe a inteligência. Empregado a princípio, sem plano preestabelecido, sem tempo determinado, reconheceu-se que, não obstante sua evidente vantagem sobre o ensino até então praticado, apresentava inconvenientes a que convinha fossem removidos ${ }^{17}$.

\section{A ARITMÉtICA DE CONDORCET NAS VOZES MANIFESTAS EM REVISTAS DA INSTRUÇÃO PÚBLICA}

Quem foi Condorcet? Por que a obra Moyens d'apprendre à compter sûrement et avec facilite (1794), escrita em 1794, para a instrução pública da França revolucionária, traduzida no Brasil, no ano de 1883 e intitulada

\footnotetext{
17 Revista O Ensino Primario (1884, p. 27).
} 
Methodo para aprender a contar com segurança e facilidade, passou a circular no Brasil, nos anos 70 do século XIX?

Jean-Antoine-Nicolas Cartat (1743-1794), o Marquuês de Condorcet, foi um brilhante intelectual do século das luzes, uma figura relevante na matemática, na filosofia e na educação. "Pertencente à geração que sucedeu à de Diderot, D'Alember e Condillac, Condorcet é frequentemente denominado o último dos filósofos iluministas (GOMES, 2008, p. 2015). Outro ponto forte foi a sua atuação na Revolução Francesa, pois colaborou para estabecer as bases doutrinárias do sistema educativo burgês e definir o projeto educativo liberal republicano, firmado nos postulados teóricos e ideológicos da ilustração e dos filósofos iluministas que influenciaram o pensamento pedagógico contemporâneo.

No Brasil, um dos meios de unificar o sistema de ensino primário na província, foi a padronização dos livros escolares. A necessidade de bons compêndios foi sempre proclamada pelos diretores de instrução pública, que sugeriam a distribuição de prêmios aos melhores elaborados pelos professores, como um incentivo à criação dessas obras (FARIAS, 2014).

Já no contexto da França pós-revolucionária, Condorcet, ao obter a informação a respeito da abertura do concurso público para a seleção dos livros elementares a serem usados na instrução, iniciou efetivamente a elaboração de um texto, no qual pretendia abordar não somente os elementos da aritmética, mas também, os de geometria, teoria das proporções e das equações do primeiro grau e outros tópicos. Desta forma, o livro de Condorcet foi colocado na lista dos livros elementares, autorizados por um Conselho de Instrução Pública. A forte repercussão dessas concepções foi responsável ainda pela publicação, no Brasil, de pelo menos duas edições do livro de aritmética de Condorcet - uma delas em português, de 1883, publicada pela Livraria Nicolau Alves (GOMES, 2001).

Entendemos que, diferentemente do que se propunha Condorcet, o projeto educacional que visou a uma educação nacional, pautado em ideias francesas, teve como propósito formar a moral e dar aos futuros cidadãos o sentimento de pertinência fraternal e nacional, bem como, o do 
que é ser o bom cidadão. Os projetos com esse propósito conferem à escola, a função de conformar o educando do ponto de vista físico, moral e, finalmente, intelectual.

Na visão do filósofo Condorcet, a instrução pública visa especialmente ao desenvolvimento das faculdades intelectuais e das aptidões técnicas pela aquisição dos conhecimentos e pelo exercício individual da razão, em oposição à chamada educação nacional. Neste mesmo sentido, Condorcet vê, na escola primária, o local onde se ensina "o que cada indivíduo necessita saber para conduzir-se a si mesmo e desfrutar da plenitude de seus direitos" (GOMES, 2008, p. 229; 230). Esta posição opõe-se à filosofia positivista presente no discurso dos documentos oficiais e dos textos midiáticos que constituem o arquivo de nossa pesquisa. Como diria Derrida, "a sua 'presença' [no caso, a da concepção da escolarização primária com um direito político dos cidadãos] se insinua como rastros ou espectros chegando de algum outro lugar; ela, entretanto, se estabelece e se firma mediante uma relação entre espectralidade e escritura; os seus rastros, os seus espectros são os fantasmas da escritura" (WOLFREYS, 2009, p. 196).

A expressão "compêndios mais elementares" nos leva ao rastro do plano de Condorcet para a instrução pública, no que diz respeito à Matemática, no quadro dos progressos do espírito humano e à educação matemática. Condorcet fez questão de enfatizar a importância do conhecimento elementar da Aritmética - explicitamente, para satisfazer as necessidades imediatas da vida. Condorcet argumentava que não poderia haver verdadeira igualdade política, senão entre sujeitos com um mínimo de autonomia intelectual.

Seguindo, ainda, os rastros do autor, vemos que Condorcet propunha, no documento "Informe sobre a organização geral da instrução pública, apresentado à Assembleia em abril de 1792", que, nas escolas primárias e secundárias, os "livros elementares" fossem escolhidos por intermédio de um concurso aberto a todos os cidadãos, devendo o poder público indicar aqueles mais adequados à instrução. Ou seja, os manuais funcionando 
como fonte privilegiada da difusão dos ideais iluministas. Neste sentido, o plano de Condorcet mobiliza essa função dos livros elementares.

Vozes da Revista do Ensino

A revista do Ensino $\left(1^{\circ}\right.$ anno- N. 3. março de 1883 e $1^{\circ}$ Anno - N. 4 abril de 1883) - Livraria Nicolau Alves, publicou fascículos da Arithmetica de Condorcet intitulados: ARITHMMETICA: meio de aprender a contar com segurança e facilidade, por CONCORCET. Os fascículos publicados nessa Revista compõem o livro escolar Método para aprender a contar com segurança e facilidade, do marquês de Condorcet, destinado ao ensino primário.

FIGURA 4: Revista do Ensino

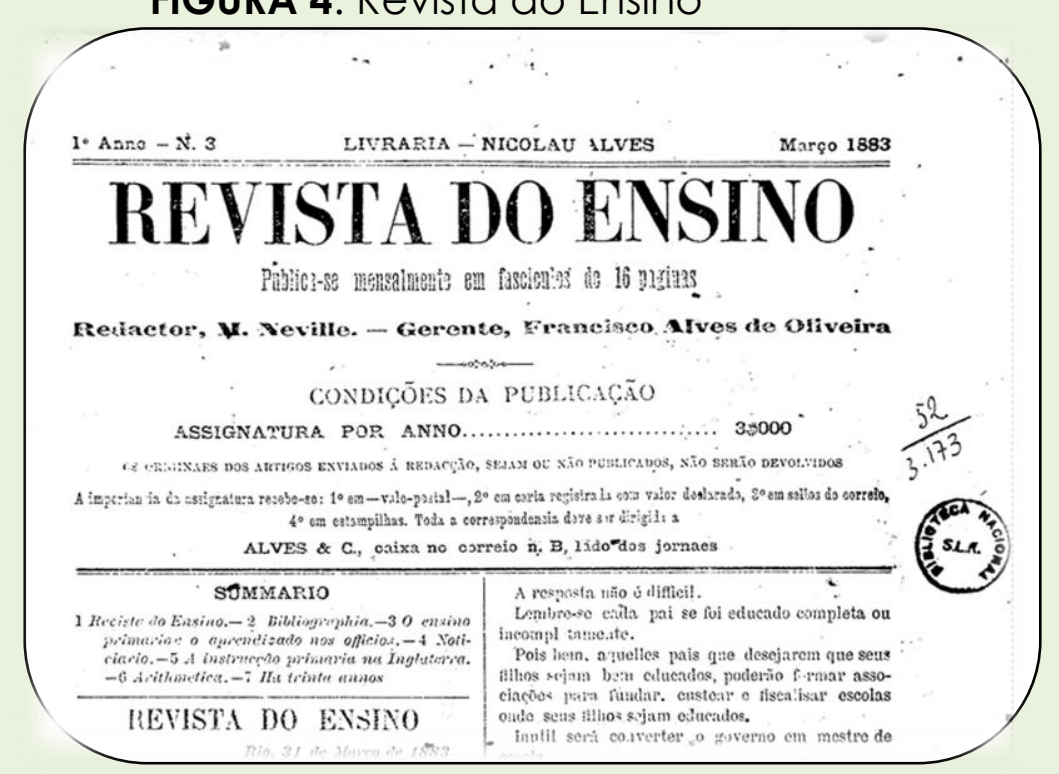

Fonte: Material microfilmado da Fundação Biblioteca Nacional do Rio de Janeiro. Farias (2014).

Gomes (2008, p. 242) se refere ao manual de aritmética de Condorcet, no original Moyens d'apprendre à compter sûrement et avec favilité, entendendo tratar-se de doze lições de aritmética, em que Condorcet mobiliza representações dos números no sistema decimal indo-arábico e das operações com esses números, efetuadas por intermédio de algoritmos que aproveitam todas as vantagens desse sistema, e que são exatamente os mesmos trabalhados ainda hoje na educação matemática básica.

Este manual de Condorcet é um livro elementar de matemática, no qual se expõem as regras elementares da aritmética - o funcionamento do 
sistema de numeração, bem como as ideias e os algoritmos da adição, subtração, multiplicação e divisão (GOMES, 2008, p. 246).

No manual, as três primeiras lições abordam a ideia de numeração decimal por palavras e algarismos, os princípios do sistema de numeração e a representação dos números desse sistema. A quarta lição se dedica à adição e à subtração, e a sexta, à prova dessas duas operações pela utilização de suas operações inversas. A sétima e a oitava lições expõem a ideia e o algoritmo da multiplicação; a nona e a décima tratam da divisão; a décima primeira introduz as frações a partir da divisão; a última focaliza as provas dessas duas operações por meio de suas inversas (GOMES, 2008, p. 247).

Na pesquisa de Farias (2014), não foram consideradas nem a primeira lição do manual de aritmética de Condorcet e nem as seis últimas lições. Talvez, um dos motivos dessa não consideração tenha sido o de que "faltam à edição do manual de 1854 algumas partes do texto completo escrito por Condorcet referentes à primeira lição, bem como um prefácio (GOMES, 2008, p. 252 apud SCHUBRING, 1988).

Em março de 1883, a Revista do Ensino trouxe a (continuação) da Segunda lição, e em abril da terceira à sexta lição.

\section{Segunda Lição}

Eis qual o systema de numeração em uso entre nós:

Um somado a dez diz-se dez e um ou onze. Segue assim até o número dezenove. Para exprimir o número seguinte ou um somado a dez e nove não diremos dez e dez, pois a continuar chegaríamos a formar nomes longos que seria difícil compreender e pronunciar. Chama-se, pois, a este número dienta ou vinte (transcrito como o original).

\section{(...)}

\section{Terceira Lição}

Até aqui só sabemos exprimir por algarismos os números um, dous, até nove, com auxilio dos caracteres

\section{$1,2,3,4,5,6,7,8,9$.}

Já fizemos ver que se como estes caracteres quiséssemos adaptar um para cada numero a memoria não os poderia guardar além de um termo muito próximo; foi, portanto, necessário adaptar um meio de exprimir todos os números com poucos caracteres, por exemplo, com os nove mencionados. 
Para isso admittio-se que, exprimindo o primeiro algarismo o numero de unidades até nove, o que Ihe ficasse imediatamente à esquerda exprimisse tantas dezenas quantas unidades ele exprimiria se tivesse isolado (transcrito como o original).

\section{(...)}

\section{Quarta Lição}

Acabou-se de ver como se formavam os números, reunindo unidades, dezenas a dezenas, centenas a centenas, etc.

Suponhamos agora conhecer dous números cuja somma nos seja necessário determinar. Isto é, conhecer o numero que resultara da reunião dos conhecidos, ou o numero total de objetos representados, parte por um destes números e parte pelo outro.

Seja, por exemplo, que te damos 13 objetos emum lugar e 26 em outro, e que queiramos saber quantos são os objetos ao todo: isto se conseguirá somando os dois números dados, ou reunindo 13 a 26.

Nota-se imediatamente, que 13 compõem-se de 1 dezena e de 3 unidades, que 26 compõem-se de 2 dezenas e 6 unidades; sabemos já que 3 unidades e 6 unidades formam 9 unidades, que 1 dezena e 2 dezenas formam 3 dezenas: assim, pois, os dois números encerram ao todo 9 unidades e 3 dezenas: sua somma é pois 39.

\section{(....) \\ Quinta lição}

Até aqui temos visto como podem ser formados todos os números pela adição, mais ou menos repetida, de unidades ou de outros números, sucessivamente: o número dez, por exemplo, pode ser formado adicionandose a 7 três unidades, assim: $7+3=10$, será facil portanto concluir que se de dez se tirarem sucessivamente três unidades o resto será sete e que 10-3=7

$$
\text { (....) }
$$

\section{Sexta Lição}

É possivel cometer engano fazendo uma adição ou uma subtração. Seria, pois, conveniente conhecer um mrio de verificar a operação. Este meio é uma outra operação que deve dar um certo resultado de antemão conhecido, se a primeira operação estiver certa.

Assim, tendo-se subtraído um numero de outro, por exemplo, 17 de 51; achouse uma diferença que será então d 37. Se esta diferença de 37 for a verdadeira, srá necessário que, adicionando-a ao menor numero 17, ache-se de novo o maior 54. Com efeito, se 17 mais 37 são 54, tirando 17 de 54 restarão 37.

$\mathrm{Na}$ análise realizada por Gomes (2008), embora as lições de Condorcet incluam boa quantidade de exemplos resolvidos e comentados, não há exercícios propostos após qualquer das lições. "O que parece dirigir 
Concorcet é o propósito de ensinar, primordialmente, os algoritmos denominados fórmulas - das operações" (p. 247).

O manual apresenta as ideias que the estão associadas, em seguida motiva a introdução da respectiva fórmula como instrumento abreviador e facilitador de um trabalho que poderia ser, de outro modo, longo e fatigante, e, finalmente, mostra o funcionamento dessa fórmula com exemplos, fundamentando-se, sempre, nas propriedades do sistema de numeração - base 10, princípio posicional e zero ( GOMES, 2008).

\section{CONSIDERAÇÕES FINAIS}

Retomamos a questão: por que a obra Moyens d'apprendre à compter sûrement et avec facilite (1794), de Condorcet circulava em revistas de educação, no Brasil dos anos 80 do século XIX? Entendemos que o projeto educativo brasileiro, da segunda metade do século XIX, tinha como base as doutrinas positivistas. Esta era a visão filosófica em voga. Por volta de meados da década de 1880, nas províncias do Rio de Janeiro e de São Paulo, muitos professores-mestres estavam fascinados pelas doutrinas de Comte.

Entendemos que, naquele tempo, a educação escolarizada era vista como projeto civilizatório da sociedade brasileira, para ser realizado por intermédio das escolas de primeiras letras. Assim, na segunda metade do século XIX, o positivismo comteano foi uma corrente filosófica que impactou expressivamente os campos político e educacional brasileiros. O Positivismo assumiu para si a tarefa de dar à educação um fundamento e um conteúdo ético que pudessem ser aceitos por todos. O seu programa consistiu em formar uma consciência moral e social que, desde as bases, pudesse inspirar todos os idealismos humanos. A educação positiva supõe a subordinação, entre outras coisas, "do progresso à ordem"18.

O núcleo da filosofia de Comte radica na ideia de que a sociedade só pode ser "convenientemente" reorganizada através de uma completa

\footnotetext{
18 Comte (1978).
} 
reforma intelectual e moral do homem. O discurso era de aceitação da filosofia moralista fundamentada na noção de ordem e de progresso de rejeição das inovações didático-metodológicas no plano da educação escolar (FARIAS, 2014), rejeição esta que, no caso do ensino escolar da aritmética, implicava na rejeição do método intuitivo de se ensiná-la, tal como ela era apresentada na obra de Allison Norman Calkins, intitulada Primeiras lições de coisas: manual de ensino elementar para uso dos pais e professores, obra esta que traduzida para o português pelo próprio Rui Barbosa, havia sido, segundo Lourenço Filho, oficialmente aprovada para uso nas escolas públicas, tendo circulado pelas escolas normais brasileiras até por volta do ano de 1916 (SOUZA, 1996, p. 131); (MIGUEL \& VILELA, 2008, p. ).

Segundo Miguel \& Vilela (2008), o livro de Calkins nos atesta que perspectivas empírico-intuitivas já haviam começado a participar da formação de professores primários em nosso país desde, pelo menos, o ano de 1886 e é o próprio Ruy Barbosa - grande entusiasta do ensino intuitivo, isto é, das lições de coisas -, que, no prefácio à primeira edição brasileira desta obra, assim se dirige aos pais e professores para caracterizar a concepção de ensino e de aprendizagem que orientava este novo modo de se ensinar e aprender a aritmética, em explícita oposição à concepção verbalista mecânico-mmemônica de ensino-aprendizagem que orientava o método tradicional com base no qual a aritmética vinha sendo ensinada e aprendida nas escolas de primeiras letras, bem como na formação de professores:

Não pela descripção oral, mas pela inspecção real dos objetos, há de começar o ensino. Por essa inspecção é que se adquire o conhecimento certo das coisas. O que efetivamente se vê, mais depressa se imprime na memória, do que verbalmente expendido ou enumerado cem vezes. (...) Outrossim, disse, ao cerrar do século dezoito, o grande educador suísso Pestalozzi: - A observação é absolutamente a base de todo o conhecimento. O que antes de tudo, pois, se deve ter em mira, na educação, é habituar o menino a observar exacta, e depois a exprimir correctamente o resultado do que observar (RUY BARBOSA, in: CALKINS, 1886). 
Mas, conforme a caracterizamos acima, a concepção de ensinoaprendizagem que orienta a Aritmética de Condorcet - primeira obra inclusa na categoria "Ciência" da biblioteca positivista recomendada por Comte - não se identifica nem com a concepção verbalista mecânicomnemônica defendida pelo método tradicional e nem com a concepção empírico-intuitiva defendida por Calkins e Ruy Barbosa.

Se examinarmos as três diferentes concepções de aprendizagem matemática mobilizadas pelas aritméticas que se orientavam ou pelo método tradicional, ou pelo método intuitivo, ou ainda, pelo método acionado por Condorcet em sua Aritmética, através de uma perspectiva wittgensteiniana da produção de significados, não seria difícil constatar que a concepção de ensino e aprendizagem que orienta a Aritmética de Condorcet é a que mais se aproxima tanto de uma concepção normativa da matemática sugerida por Wittgenstein (1987), quanto de uma concepção não essencialista da produção de significados sugerida pelo filósofo austríaco nas Investigações filosóficas (WITTGENSTEIN, 2009); (WITTGENSTEIN, 1979).

Uma concepção verbalista mecânico-mnemônica da aprendizagem matemática se assemelha à concepção agostiniana da aprendizagem de uma língua nativa, apresentada por Wittgenstein logo nos parágrafos iniciais das Investigações filosóficas (WITTGENSTEIN, 2009, p. 15), nas palavras do próprio Agostinho:

Quando os adultos nomeavam um objeto qualquer voltando-se para ele, eu o percebia e compreendia que o objeto era designado pelos sons que proferiam, uma vez que queriam chamar a atenção para ele. Deduzia isto, porém, de seus gestos, linguagem natural de todos os povos, linguagem que através da mímica e dos movimentos dos olhos, dos movimentos dos membros e do som da voz anuncia os sentimentos da alma, quando esta anseia por alguma coisa, ou segura, ou repele, ou foge. Assim, pouco a pouco eu aprendia a compreender o que designam as palavras que eu sempre de novo ouvia proferir nos seus devidos lugares, em diferentes sentenças. Por meio delas eu expressava os meus desejos, assim que minha boca se habituara a esses signos.

O modo como Agostinho acreditava que compreendemos os 
significados das palavras de uma língua - e, por analogia, os significados das palavras numéricas e das operações que realizamos com os signos numéricos - é criticado por Wittgenstein (2009, p.15), nos seguintes termos:

\begin{abstract}
Nestas palavras temos, ao que parece, uma determinada imagem da essência da linguagem humana, a saber: as palavras da linguagem denominam objetos - as sentenças são os liames de tais denominações. Nesta imagem da linguagem encontramos as raízes da idéia: toda palavra tem um significado. Este significado é atribuído à palavra. Ele é o objeto que a palavra designa.
\end{abstract}

Para Wittgenstein, as significações adequadas que devemos produzir tanto para palavras e enunciações em diferentes línguas nativas quanto a palavras e signos numéricos e às operações que realizamos com tais signos na aritmética usual não se dão nem através de associações fixas entre o som da palavra proferida para designar um objeto numa determinada língua e objeto designado pelo som proferido, como pensava Agostinho, e nem através de associações fixas entre o som da palavra proferida para designar um objeto e imagens sensíveis (visuais, sonoras, táteis, olfativas ou palativas), isto é, intuições desse objeto diretamente apresentadas ao aprendiz, como pensavam os proponentes do método intuitivo de aprendizagem matemática e, antes deles, os filósofos empirício-iluministas ingleses e franceses.

Para Wittgenstein, os processos de significação não constituem atividades associativas de qualquer natureza, em que a um estímulo sensorial externo faríamos corresponder uma imagem mental interna. Para ele, os processos de significação são atividades regradas, isto é, significamos seguindo regras, mesmo que não tenhamos ciência de que as estejamos seguindo. Assim, a aprendizagem de uma língua e a aprendizagem da aritmética constituem dois jogos de linguagem diferentes, porque as regras de combinação de signos sonoros de uma língua são distintas das regras de combinação de signos numéricos de nossa aritmética usual, de origem indoarábica.

Nesse sentido, poderíamos dizer que, sob uma perspectiva wittgensteiniana, apenas a concepção de ensino e aprendizagem que 
orienta a Aritmética de Condorcet seria consonante a uma concepção adequada de produção de significados para os signos numéricos e para as operações que com eles se realizam no jogo de linguagem de nossa aritmética usual, uma vez que apenas ela se propõe a justificar as quatro operações da aritmética com base nas regras do sistema de numeração decimal que herdamos dos hindus.

Isso não significa, porém, que sob uma perspectiva wittgensteiniana devêssemos condenar seja o método tradicional seja o intuitivo de ensino e aprendizagem da aritmética e eleger o método de Condorcet como o único pedagogicamente legítimo. Isso porque, ainda que, para Wittgenstein, a atividade de produzir significados adequados, para os signos que participam de um determinado jogo de linguagem, seja vista como uma atividade de seguir regras, ele não diz que, para se aprender a se movimentar adequadamente no jogo de linguagem, de se falar uma língua ou no jogo de linguagem da aritmética usual deveríamos, necessariamente, aprender as regras desses jogos, ou mesmo, termos sequer ciência delas. Uma criança aprende a falar a sua língua nativa participando diretamente dos jogos de fala dessa língua, e só, posteriormente, na escola, aprenderá as regras que orientam esse jogo de linguagem. O mesmo ocorre com crianças e adultos que adquirem competência na realização de cálculos aritméticos, mediados ou não por calculadoras eletrônicas ou outros dispositivos, sem que tenham ciência das regras que orientam ou fundamentam a realização dessas operações.

Como no final do século XIX não estava disponível uma concepção normativa da matemática, vista como um conjunto de jogos de linguagem, cada um deles visto como uma linguagem completa, e nenhuma concepção normativa e não essencialista dos processos de produção de significados, tal como nos sugeriu Wittgenstein. A introdução recomendada pelos positivistas comteanos da Aritmética de Condorcet, no cenário pedagógico brasileiro, cerca de 100 anos após a sua escrita na França pósrevolucionária, não poderia ser vista nem como surpreendente e nem como um avanço pedagógico em relação às aritméticas que se orientavam quer 
por métodos verbalistas mecânico-mnemônicos, quer por métodos intuitivos. Pelo fato de não podermos ver a Aritmética de Condorcet como um avanço pedagógico em relação às demais, esperamos ter acima esclarecido, vendo e avaliando tais aritméticas, como jogos de linguagem, sob uma perspectiva wittgensteiniana, e descolando - isto é, deixando de estabelecer uma relação de causa e efeito - o valor e os efeitos pedagógicos de tais aritméticas, sobre a aprendizagem do valor matemático de se produzir significação e fundamentação adequadas para o jogo de linguagem da aritmética usual.

Já, o fato de não podermos ver a recomendação comteana da Aritmética de Condorcet como surpreendente, poderia ser esclarecido com base na admiração, estima e apreço que Comte tinha não só pela obra matemática de D'Alembert, como também pelo novo modo de se conceber a matemática que esta obra permitiu tornar público, no contexto da França pré-revolucionária:

Com base em sua visão empírico-sensualista do conhecimento, D'Alembert via também a matemática como a mais abstrata das ciências da natureza, dotada do poder de fundamentar todas elas. Naquela época, o sistema formado pelas ciências da natureza era fundamentado nas leis da geometria euclidiana. Entretanto, D'Alembert contestou este fundacionismo geométrico e substituiu-o por um outro de natureza algébrica. Ele via a álgebra como uma língua artificial de cujas leis genéricas e abstratas poderiam ser deduzidas as leis das demais ciências explicativas da natureza (PATY, 2005, p. 172). Assim, ao delegar à álgebra o poder de traduzir concisamente o suposto desejo de ordem da natureza, ele retirou o suporte físico-espacial da physis e o substituiu por um suporte linguístico. Entretanto, ainda que tivesse de fato percebido 0 potencial analítico fundante e mais elementar da "nova língua algébrica" para traduzir a própria geometria sintética, este potencial da "nova língua" ainda se devia, bem mais, ao seu poder de abstração empírica, isto é, ao seu poder de traduzir concisamente o suposto desejo de ordem da natureza, bem como as leis que governavam as relações espaciais dos objetos no espaço físico real. No início da era moderna, Galileu - e, depois dele, também Descartes e Newton - já havia reintroduzido, no campo científico do mundo europeu, o ideal pitagórico de matematização dos fenômenos naturais, iniciativa que foi por ele expressa através do seu famoso aforismo de que "o livro da natureza se acha escrito em linguagem matemática". Entretanto, segundo Paty (2005, p. 145-146), a concepção linguística da matemática defendida por d'Alembert se diferenciava das de Galileu, Descartes e Newton no que se refere ao ramo da matemática que poderia melhor prestar este serviço de 
tradução do "desejo de ordem" da natureza. Para d'Alembert, não se tratava mais da geometria, mas sim, da álgebra. Para ele, o desenvolvimento da geometria analítica por parte de René Descartes - que, em grande medida, havia atestado a potencialidade da linguagem artificial então nascente da álgebra, a qual não mais se assemelhava à retórica verbal das diferentes línguas nativas - para realizar uma tradução analítica ou algébrica dos problemas geométricos e dos seus métodos sintéticos de resolução, havia evidenciado um novo modo de se ver a matemática, não mais como sinônimo de "geometria", mas sim, como uma "ciência das relações genéricas e abstratas", isto é, como uma aritmética abstrata generalizada (MIGUEL, 2018, nota de rodapé n. 5).

Tendo sido Condorcet discípulo de D'Alembert, a sua Aritmética foi provavelmente escrita com base nesta nova concepção linguística da Matemática de D'Alembert, que vista como "ciência das relações genéricas e abstratas", isto é, como uma aritmética abstrata generalizada passava a adquirir o poder de traduzir concisamente o suposto desejo de ordem da natureza. E era assim que Comte e os positivistas comteanos também concebiam a própria matemática. Não surpreende, portanto, que Comte tivesse recomendado e difundido a Aritmética de Condorcet como obra pedagógica de máxima potência e rigor.

No contexto da França pós-revolucionária, o pensamento e os projetos de Condorcet não só explicitaram a visão política sobre a educação, como também a fundamentação filosófica, jurídica e moral que estabeleceu as bases da escola burguesa, no contexto da República. Com relação ao plano de Condorcet para a instrução pública, Gomes (2008, p. 287) chama a atenção para um traço fundamental de seu pensamento, qual seja, a crença na educação, como meio de libertação e aperfeiçoamento do homem, bem como para o relevante papel conferido pelo filosófo à educação matemática em geral e aos conhecimentos elementares da aritmética em particular. Comte, entretanto, mesmo mantendo a concepção epistemológica da matemática preconizada por D'Alembert e Condorcet, na contra-mão do pensamento de Condorcet, despolitiza e neutraliza o papel ético e político que o filósofo iluminista conferia à educação matemática na formação escolar do cidadão. 


\section{REFERÊNCIAS}

BASTOS, M. H.C. Espelho de papel. A imprensa e a história da educação. In: ARAÚJO, J. C. S; GATTI JÚNIOR, D. (Org.). Novos temas em história da educação brasileira: instituições escolares e educação na imprensa. Campinas: Autores Associados; Uberlândia: Edufu, 2002.

BORGES, A; LEMOS D. C. de A. Os Legítimos representantes da classe: os jornais e a organização dos professores públicos primários no século XIX. Associativismo e sindicalismo no Brasil. Seminário para discussão de pesquisas e constituição de rede de pesquisadores. Rio de Janeiro, Anais. 17 e 18 de abril de 2009.

CALKINS, N.A. Primeiras lições de coisas. Rio de Janeiro: Imprensa Nacional, 1886.

CONDORCET, J. A. N. C. Methodo para aprender a contar com segurança e facilidade. Rio de Janeiro, Livraria Nicolau Alves - Successores Alves \& C., 1883.

CONDORCET, J. A. N. C. Moyens d'apprendre à compter sûrement et avec facilité. Rio de Janeiro: Igreja Positivista do Brasil, 1903.

CONTE, A. Curso de Filosofia positiva. Os Pensadores. São Paulo: Abril, 1978.

FARIAS, K. S. C. dos S. Práticas mobilizadoras de cultura aritmética na formação de professores da Escola Normal da Província do Rio de Janeiro (1868-1889): ouvindo espectros imperiais. Campinas (SP): Tese (Doutorado). Faculdade de Educação da Universidade Estadual de Campinas (UNICAMP), 2014.

GOMES, M. L. M. Um livro didático da França iluminista: a Aritmética de Condorcet. Zetetiké. V. 9, n. 1-2, 2001.

GOMES, M.L.M. Quatro visões iluministas sobre a educação matemática: Diderot, D'Alembert, Condillac e Condorcet. Campinas, SP; editora da UNICAMP, 2008.

JINZENJI, M. Y. Cultura impressa e a educação da mulher no século XIX. Belo Horizonte, ed. UFMG, 2010.

MIGUEL, A. (no prelo). O cravo de Diderot e as novas políticas educacionais: um diálogo com as luzes em uma nova época de trevas. IN: OLIVEIRA, Andreia, Maria Pereira; ORTIGÃO, Maria Isabel Ramalho (Orgs.). Sociedade Brasileira de Educação Matemática, 2018.

MIGUEL, A. Percursos indisciplinares na atividade de pesquisa em história (da educação matemática): entre jogos discursivos como práticas e práticas como jogos discursivos. Bolema, Volume 35a, p. 1-57. Rio Claro (SP): UNESP, 2010. 
MIGUEL, A.; VILELA, D. S. Práticas escolares de mobilização de cultura Matemática. Caderno CEDES, vol.28 no.74, Jan./Apr. 2008.

MOLLIER. J. Y. A Leitura e seu público no mundo contemporâneo: ensaios sobre história cultural. Belo Horizonte: Autêntica editora, 2008.

PALLARES-BURKE, M. L. G. A imprensa periódica como empresa educativa no século XIX. Caderno de pesquisa, n. 104, p. 144-161, jul. 1998.

PATY, Michel. D'Alembert ou A razão físico-matemática no século do Iluminismo. Tradução de Flávia Nascimento. São Paulo: Estação Liberdade, 2005.

SCHUBRING, G. "Introduction: Um savant des lumières. Un livre élémentaire pour la republique", in CONDORCET, Jean-Antoine-Nicolas Caritat, Moyens d'apprendre à compter sûrement et avec facilite. Appareil critique - Etudes, notes, commentaires, bibliographie. Paris: ACL Édotions, 1988.

SOUZA, E. da S. Um estudo histórico-pedagógico das crenças de futuros professores acerca do ensino-aprendizagem da noção de número natural. Dissertação de Mestrado. Faculdade de Educação. Universidade Estadual de Campinas, 1996.

TISKI. S. A Questão da moral em Augusto Comte. Tese de Doutorado, 2005. Tese (Doutorado) Departamento de Filosofia do Instituto de Filosofia e Ciências Humanas da Universidade Estadual de Campinas, Campinas, São Paulo, 2005.

WITTGENSTEIN, L. Investigações filosóficas. Tradução Marcos C. Montagnoli. Petrópolis: Vozes, 6a. edição, 2009.

WITTGENSTEIN, L. Observaciones sobre los fundamentos de la matemática. Versión de Isidoro Reguera. Madrid: Alianza Editorial, 1987.

WITTGENSTEIN, L. Philosophische Untersuchungen/Philosophical Investigations. Translated by Gertrude E.M. Anscombe, Peter M.S. Hacker, and Joachim Schulte. - Rev. 4th ed./by P.M.S. Hacker and Joachim Schulte.UK: WileyBlackwell Publishing Ltd., 2009.

WOLFREYS. J. Compreender Derrida. Trad. Caesar Souza. Petrópolis, Rio de Janeiro: Vozes, 2009.

Recebido em: 28 de setembro de 2018 Aprovado em: 07 de fevereiro de 2019 